\title{
High frequency oscillation for preterm infants with severe respiratory failure
}

\author{
V Chan, A Greenough, H R Gamsu
}

\begin{abstract}
High frequency oscillation (HFO) as rescue treatment for preterm infants with severe respiratory failure has been assessed and prognostic factors identified. Thirty six infants with a median gestational age of 27 weeks were studied. Immediately before transfer to HFO, the infants were receiving an inspired oxygen concentration of $\geqslant 85 \%$ and/or a mean airway pressure of $\geqslant 12 \mathrm{~cm} \mathrm{H}_{2} \mathrm{O}$ and had a median alveolar-arterial oxygen gradient $\left(\mathrm{A}-\mathrm{aDO}_{2}\right)$ of $73 \cdot 28 \mathrm{kPa}$ (range 49.34-89.91). Seventeen infants subsequently died. Comparison of those 17 with the remaining 19 infants demonstrated that respiratory distress syndrome and persistent fetal circulation were associated with a significantly better outcome than pulmonary airleak. The $\mathrm{A}-\mathrm{aDO}_{2}$ after two and six hours on HFO was significantly higher in those infants who survived compared with those who died. We conclude that a diagnosis of pulmonary airleak and failure to show early improvement in respiratory status indicate a poor prognosis when HFO is used as rescue treatment.

(Arch Dis Child 1994; 70: F44-F46)
\end{abstract}

Despite improvements in mechanical ventilation, infants still die of severe respiratory failure. ${ }^{1}$ To improve their outlook new techniques of respiratory support have been introduced. It is claimed that extracorporeal membrane oxygenation (ECMO) substantially increases survival, even when applied to infants with a predicted mortality of $80 \%$ or greater. $^{2}$ Unfortunately, because of increased risk of intracerebral haemorrhage, ${ }^{3}$ ECMO is thought not to be suitable for premature infants. High frequency oscillation (HFO) can be used to support those vulnerable infants and may reduce the risk of residual chronic lung disease. ${ }^{4}$ HFO, however, can also give rise to serious complications. ${ }^{5}$ Therefore, it is important to use this technique only in those babies most likely to benefit from it. The aim of this study was, therefore, to assess the efficacy of HFO as rescue treatment for preterm infants with severe respiratory failure and to identify those factors that have prognostic significance.

Department of Child Health, King's College Hospital, London SE5 9RS

$\mathrm{V}$ Chan

A Greenough

H R Gamsu

Correspondence to: Professor Greenough.

Accepted 14 September 1993

\section{Patients and methods}

METHODS

Premature infants with respiratory failure deemed to be unresponsive to conventional ventilation by the clinician in charge of the case were changed to HFO. To maintain blood gases within the desired range $(\mathrm{pH} 7 \cdot 25-7 \cdot 4$, arterial oxygen tension $\left(\mathrm{PaO}_{2}\right) 6.67-9.33 \mathrm{kPa}$, and arterial carbon dioxide tension $\left(\mathrm{PaCO}_{2}\right)$ 5.33-8.00 kPa), when they were transferred from conventional ventilation to $\mathrm{HFO}$, all infants needed an inspired oxygen concentration $\left(\mathrm{FIO}_{2}\right)$ of $85 \%$ or greater and/or a mean airway pressure of at least $12 \mathrm{~cm} \mathrm{H}_{2} \mathrm{O}$.

HFO was provided by a SensorMedics 3100 oscillator, fitted with adjustable controls including frequency, fractional inspiratory time, amplitude, and mean airway pressure. When changing to $\mathrm{HFO}$ the same $\left(\mathrm{FIO}_{2}\right)$ was maintained, a frequency of $10 \mathrm{~Hz}$ and a fractional inspiratory time of 0.30 were used. The previously set mean airway pressure was raised by $2 \mathrm{~cm} \mathrm{H}_{2} \mathrm{O}^{6}{ }^{\text {The amplitude was increased }}$ by adjusting the displacement or power of the oscillator until visible chest wall vibration was observed. During subsequent HFO, the settings were adjusted to maintain the blood gases within the desired range (see above) and at the same time avoiding lung overdistension. Once improvement in respiratory status was seen, the $\mathrm{FIO}_{2}$ was reduced in preference to lowering the mean airway pressure.

Blood gases were checked immediately before and at least two and six hours after transfer to HFO and more frequently when clinically indicated. All blood samples were taken from an indwelling arterial line that had been inserted for clinical purposes. The nursing staff recorded all ventilation and oscillation settings hourly. From the nursing records and the arterial blood gases alveolar-arterial oxygen gradients $\left(\mathrm{A}-\mathrm{aDO}_{2}\right)$ and the arterial/alveolar (a/A) ratio were calculated. The outcome of the infants was documented from the medical records.

\section{ANALYSIS}

Differences between infants who died and survived were assessed for statistical significance using either Fisher's exact test or the Wilcoxon rank sum test as appropriate.

\section{PATIENTS}

The 36 infants who were included in the study had a variety of diagnoses (table 1).

Table 1 Diagnoses of infants supported by HFO (number of infants given surfactant in parentheses) 
Respiratory distress syndrome was diagnosed if the infant developed respiratory distress before 4 hours of age and had a symmetrical ground glass appearance on the chest radiograph. In addition no infectious agent had been isolated in the first 48 hours of life. Persistent fetal circulation was diagnosed in infants who were severely hypoxic, who had a right to left shunt at atrial and ductal levels due to pulmonary hypertension, but in whom a structurally normal heart was confirmed echocardiographically. Pulmonary hypoplasia was diagnosed if high peak pressures $\left(>30 \mathrm{~cm} \mathrm{H}_{2} \mathrm{O}\right)$ were required both for resuscitation and during ventilation for at least the first week of life and this was associated with small volume lungs on the chest radiograph. In those infants who died, the diagnosis was confirmed on postmortem examination by finding a reduced lung weight and a radial alveolar count of less than 4. Pulmonary airleak was diagnosed if the infant had pulmonary interstitial emphysema or pneumothorax.

The median gestational age of the infants was 27 weeks (range 23-36), birth weight $868 \mathrm{~g}$ (428-3000), and postnatal age 2.5 days (range $0 \cdot 1-23)$. The infants were all initially ventilated using Sechrist IV ventilators and oral endotracheal tubes. Immediately before transfer to $\mathrm{HFO}$ the infants were receiving a median peak inspiratory pressure of $31 \mathrm{~cm}$ $\mathrm{H}_{2} \mathrm{O}$ (range 19-46), mean airway pressure of $13 \mathrm{~cm} \mathrm{H}_{2} \mathrm{O}$ (range $8-30$ ), and $\mathrm{FiO}_{2}$ of $95 \%$ (range 60-100).

The majority of infants (table 1) had received exogenous surfactant replacement treatment in the first $\mathbf{4 8}$ hours of life, as their $\mathrm{a} / \mathrm{A}$ ratio had been less than $0 \cdot 22$. At the time of transfer the infants' median a/A ratio was 0.079 (range $0.03-0 \cdot 148$ ).

This study was approved by the King's College Hospital ethics committee.

Table 2 Patient characteristics and ventilator requirements prior to transfer to HFO; figures are median (range)

\begin{tabular}{lcc}
\hline & $\begin{array}{l}\text { Died } \\
(n=17)\end{array}$ & $\begin{array}{c}\text { Survived } \\
(n=19)\end{array}$ \\
\hline Gestational age (weeks) & $26(25-31)$ & $28(23-36)$ \\
Birth weight (g) & $804(590-1906)$ & $816(428-3000)$ \\
Postnatal age (days) & $3(0 \cdot 1-8)$ & $2(0 \cdot 2-23)$ \\
Mean airway pressure $\left(\mathrm{cm} \mathrm{H}_{2} \mathrm{O}\right)$ & $13(11-30)$ & $13(9-24)$ \\
Ventilator rate (/min) & $76(40-100)$ & $69(45-100)$ \\
FiO $_{2}(\%)$ & $97(71-100)$ & $93(60-100)$ \\
\hline
\end{tabular}

Table 3 Changes in mean airway pressure and oxygenation immediately before ( 0 ) and at 2 and 6 hours after transfer to HFO; figures are median (range)

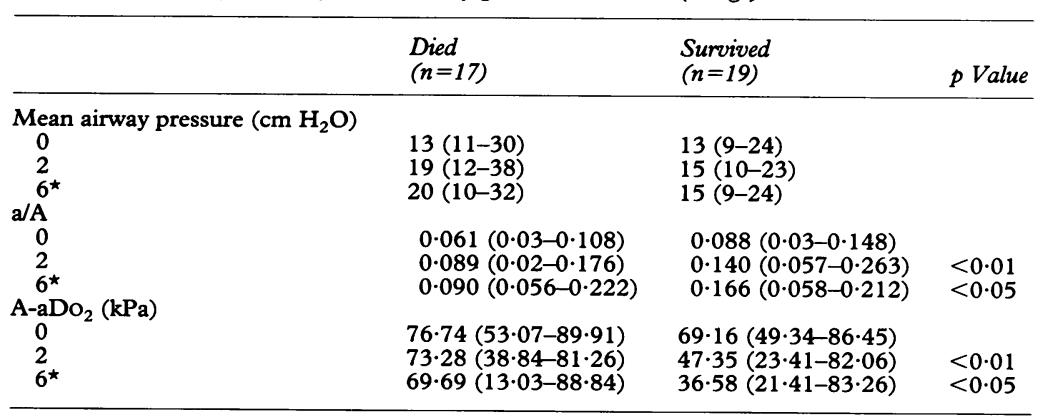

^Two infants had died by the 6 hour recordings.

\section{Results}

Despite using HFO, 17 infants subsequently died. All died of respiratory failure, but in one case this was complicated by candida septicaemia, in six by severe air leak, and three had terminal pulmonary haemorrhage. The median duration of $\mathrm{HFO}$ overall was $2 \cdot 7$ days (range 0.08-11.1). As expected, the 17 infants who died spent significantly less time on the oscillator (median 1.0 days, range $0 \cdot 08-11 \cdot 1$ ) compared with a median of 2.5 days (range $1 \cdot 0-10 \cdot 4)$ in the survivors, $\mathrm{p}<0.01$.

During HFO, no infant developed a new intracerebral bleed, but six cases had worsening of existing bleeds and all died. Five infants who had pulmonary interstitial emphysema before starting HFO developed pneumothoraces and two infants with pulmonary hypoplasia developed both pulmonary interstitial emphysema and pneumothorax on HFO.

A significantly greater proportion of infants who had severe respiratory distress syndrome as the primary diagnosis survived than did infants with pulmonary air leak $(p<0.02)$ or with pulmonary hypoplasia $(p<0.05)$. The outcome of the infants with persistent fetal circulation was also better than the infants with pulmonary air leak $(p<0.03)$ (table 1$)$. Overall there was no significant difference in surfactant usage between infants who died or survived (table 1). The birth weight, gestation or postnatal age did not differ significantly between the two groups (table 2). Ventilator rate tended to be higher before transfer to HFO and the inspired oxygen concentration was significantly greater $(p<0.05)$ in the group who died.

In the 36 infants overall there was a significant progressive improvement in the $\mathrm{A}-\mathrm{aDO}_{2}$ over the first six hours on HFO. Before HFO, the median $\mathrm{A}-\mathrm{aDO}_{2}$ was $73.28 \mathrm{kPa}$ (range 49.34-89.91), after two hours on HFO 55.66 $\mathrm{kPa}$ (range 23.41-82.06), $\mathrm{p}<0.01$, and after six hours on HFO, $46.82 \mathrm{kPa}$ (range 13.03-88.84), $\mathrm{p}<0.01$. Although there was no significant difference in the median $\mathrm{A}-\mathrm{aDO}_{2}$ before transfer to $\mathrm{HFO}$, at two and six hours the median $\mathrm{A}-\mathrm{aDO}_{2}$ was significantly lower in the infants who subsequently survived compared with those who died, $\mathrm{p}<0.01$ and $\mathrm{p}<0.05$ respectively (table 3 ).

\section{Discussion}

The overall survival of 19 of $36(53 \%)$ of our patients is most encouraging. Many of our infants, before $\mathrm{HFO}$, had an $\mathrm{A}-\mathrm{aDO}_{2}$ which, in term infants, has been an indication of an $80 \%$ mortality. ${ }^{7}$ Blum-Hoffman et al reported a survival rate $(47 \%)$ similar to ourselves, ${ }^{8}$ but their patients were more mature than those of the present series. These results do suggest that $\mathrm{HFO}$ has a role as rescue treatment for premature infants with severe respiratory failure.

There has been concern that HFO may be associated with increased intracerebral haemorrhage. ${ }^{5}$ In the present study no infant experienced a new intracerebral bleed during oscillation and in less than $20 \%$ of our patients extensions to existing haemorrhages occurred. 
As all our patients were very immature and critically ill before starting $\mathrm{HFO}$, more instances of cerebral haemorrhage might have been expected.

Animal studies have suggested that HFO can be efficacious in hyaline membrane disease even after lung injury has been established. ${ }^{9}$ The present results confirm that finding, given the high survival rate of our critically ill infants who had severe respiratory distress syndrome. In addition respiratory distress syndrome was associated with a better outcome than the other diagnosis in the babies who were included in our trial.

We did not find HFO to be helpful in infants with pulmonary hypoplasia or established airleak. The majority of those patients died. Although the numbers are small, our findings are supported by the equally poor results in the series reported by Blum-Hoffman et al in more mature infants who had these diagnoses. ${ }^{8}$ In both the present and this earlier study ${ }^{8}$ the airleak frequently worsened.

In survivors we noted an early and significant improvement in oxygenation, similar to that reported in premature baboons with established lung injury treated with HFO. ${ }^{9}$ Unfortunately, in the baboons, despite the acute improvement in blood gases, at 24 hours there was no significant difference in the chest radiograph appearance of animals treated using conventional ventilation compared with the group on HFO. It was thus postulated that, although HFO might interrupt the progression of lung injury, it did not reverse it. ${ }^{9}$ Even with such a limited effect of HFO in our group of preterm infants it was compatible with a higher than expected survival rate of critically ill patients.

Although many of the patients improved, as indicated by an increase in the a/A ratio and $\mathrm{A}-\mathrm{aDO}_{2}$ this was not accompanied by a reduction in mean airway pressure level. This, however, was due to our policy of reducing the inspired oxygen concentration before altering the pressure level ${ }^{6}$ and reflects a concern for the damaging effects of high inspired oxygen concentrations. ${ }^{10}$

During HFO, oxygenation is determined by mean airway pressure and it is usually necessary to achieve a critical mean airway pressure level before any effect is seen. ${ }^{6}$ On transfer to HFO, following our usual protocol, ${ }^{6}$ the mean airway pressure was increased by at least $2 \mathrm{~cm}$ $\mathrm{H}_{2} \mathrm{O}$ in all the patients; in the survivors this was associated with a significant improvement in oxygenation at six hours. In the group who did not survive, the mean airway pressure level over the first six hours was increased by a median of $7 \mathrm{~cm} \mathrm{H}_{2} \mathrm{O}$ without, however, a corresponding improvement in oxygenation. This presumably reflected the severity of their lung disease and not the inadequacy of treatment. ${ }^{6}$

Our results demonstrate that it was not possible to identify before HFO those infants who would benefit from $\mathrm{HFO}$ from either the mean airway pressure level, the a/A ratio, or $\mathrm{A}-\mathrm{aDO}_{2}$ (table 3). An early (within six hours) improvement in oxygenation, however, was associated with survival, as has been also noted by Blum-Hoffman et al in more mature patients. ${ }^{8}$ Our data, therefore, suggest that critically ill infants need only be committed to a very short trial of HFO from which it would be possible to predict the likelihood of long term benefit.

Dr V Chan is supported by the Children Nationwide Medical Research Fund. We thank Ms Sue Williams for secretarial assistance.

1 Chan V, Greenough A, Gamsu HR. Neonatal complications of mechanical ventilation in extremely preterm infants. Eur F Pediatr 1992; 151: 693-6.

2 Nicks JJ, Bartlett RH. Extracorporeal membrane oxygenation and other new modes of gas exchange. In: Carlo WA, Chatburn RL, eds. Neonatal respiratory failure. Chicago: Year Book Medical Publishers 1988: 394-407.

3 Bartlett RH, Gazzaniga AB, Toomasian J, Coran AG, Roloff D, Rucker R. Extracorporeal membrane oxygenation (ECMO) in neonatal respiratory failure. 100 cases. Ann Surg 1986; 204: 236-45.

4 Clark RH, Gerstmann DR, Null DM Jr, DeLemos RA. Prospective randomized comparison of high-frequency oscillatory and conventional ventilation in respiratory distress syndrome. Pediatrics 1992; 89: 5-12.

5 The HIFI Study Group. High frequency oscillatory ventilation compared with conventional intermittent mechanical ventilation in the treatment of respiratory failure in premature neonates. $N$ Engl F Med 1989; 320: 88-93.

6 Chan V, Greenough A. Determinants of oxygenation during high frequency oscillation. Eur $\mathcal{f}$ Pediatr 1993; 152 350-3.

7 Beck R, Anderson KD, Pearson GD, Cronin J, Miller MK Short BL. Criteria for extracorporeal membrane oxygenation in a population of infants with persistent pulmonary tion in a population of infants with persistent pulmonary hypertension.

8 Blum-Hoffman E, Kopotic RJ, Mannino FL. High frequency oscillatory ventilation combined with intermittent mandatory ventilation in critically ill neonates. Eur $\mathcal{f}$ Pediatr 1988; 147: 392-8.

9 DeLemos RA, Coalson JJ, DeLemos JA, King RJ, Clark RH, Gerstmann DR. Rescue ventilation with high frequency oscillation in premature baboons with hyaline membrane disease. Pediatr Pulmonol 1992; 12: 29-36.

10 Northway WH, Rosan RC, Porter DY. Pulmonary disease following respirator therapy of hyaline membrane disease. N Engl f Med 1967; 267: 357-67. 